\title{
Intravitreous Injection of Interleukin-6 Leads to a Sprouting in the Retinotectal Pathway at Different Stages of Development
}

\author{
Grasielle D. Menezes Vanessa G. Goulart Sheila Espírito-Santo \\ Priscilla Oliveira-Silva Claudio Alberto Serfaty Paula Campello-Costa \\ Programa de Neurociências, Departamento de Neurobiologia, Universidade Federal Fluminense, Niterói, Brazil
}

\author{
Key Words \\ Interleukin-6 · Central nervous system · Retinotectal \\ projections $\cdot$ Plasticity
}

\begin{abstract}
Objective: The development of retinotectal pathways form precise topographical maps is usually completed by the third postnatal week. Cytokines participate in the development and plasticity of the nervous system. We have previously shown that in vivo treatment with interleukin 2 disrupts the retinocollicular topographical order in early stages of development. Therefore, we decided to study the effect of a single intravitreous injection of IL-6 upon retinotectal circuitry in neonates and juvenile rats. Materials and Methods: Lister Hooded rats received an intravitreous injection of IL-6 (50 ng/ml) or vehicle (PBS) at either postnatal day (PND)10 or PND30 and the ipsilateral retinotectal pathway was evaluated 4 or 8 days later, respectively. Results: Our data showed that, at different stages of development, a single IL-6 intravitreous treatment did not produce an inflammatory response and increased retinal axon innervation throughout the visual layers of the superior colliculus. Conclusions: Taken together, our data provide the first evidence that a single intravitreous injection with IL-6 leads to sprouting in the subcortical visual connections and suggest that small changes in IL-6 levels might be sufficient to impair the correct neuronal circuitry fine-tuning during brain development.
\end{abstract}

(c) 2016 S. Karger AG, Basel

\section{KARGER}

C) 2016 S. Karger AG, Basel

1021-7401/16/0232-0081\$39.50/0

E-Mail karger@karger.com

www.karger.com/nim

\section{Introduction}

Interleukin-6 (IL-6) belongs to the neuropoietic cytokine family that is present in the central nervous system, playing a large variety of functions $[1,2]$. This interleukin increases the survival of retinal ganglion cells (RGCs) in culture [3-5] and also in an in vivo model of elevated ocular pressure $[6,7]$. Other studies have associated IL-6 to synaptic plasticity since endogenous IL-6 inhibition can prolong long-term potentiation and improve memory [8-11]. Also, IL-6 modulates both excitatory and inhibitory synapses and reduces paired-pulse inhibition [12]. IL-6 also has an effect upon dendritic spine morphology, leading to the formation of new synaptic contacts [12]. Recent studies have indicated a relationship between increased levels of IL-6 and developmental diseases with impaired synapse and dendritic spine formation or elimination [13-15]. Indeed, both the behavior and brain morphological alterations observed in autism are blocked by anti-IL- 6 antibody [16]. Therefore, IL-6 might be a key component for the development of synaptic contacts and changes in its levels might be sufficient to impair the correct brain connectivity.

The retinotectal pathway is a useful model to study the development of central connections and the mechanisms underlying this process. It is formed by RGC axons that innervate the superior colliculus (SC) [17]. At birth, fibers from both eyes diffusely innervate the entire SC and, dur-

Paula Campello-Costa, $\mathrm{PhD}$

Programa de Neurociências, Instituto de Neurobiologia

Universidade Federal Fluminense

Caixa Postal 100180, Niterói, RJ 24001-970 (Brazil)

E-Mail paula.campello@pq.cnpq.br 
Fig. 1. Summary of the experimental design. Pigmented rats were submitted to a single intravitreous injection of PBS (vehicle) or IL-6 (50 ng/ml) on PND10 or PND30 in the right eye. On PND13 or PND37, the animals received an intraocular injection of HRP in the opposite eye and were perfused $24 \mathrm{~h}$ later. The left SC, which received the major afferent from the PBS or IL-6 treatment eye, was evaluated.

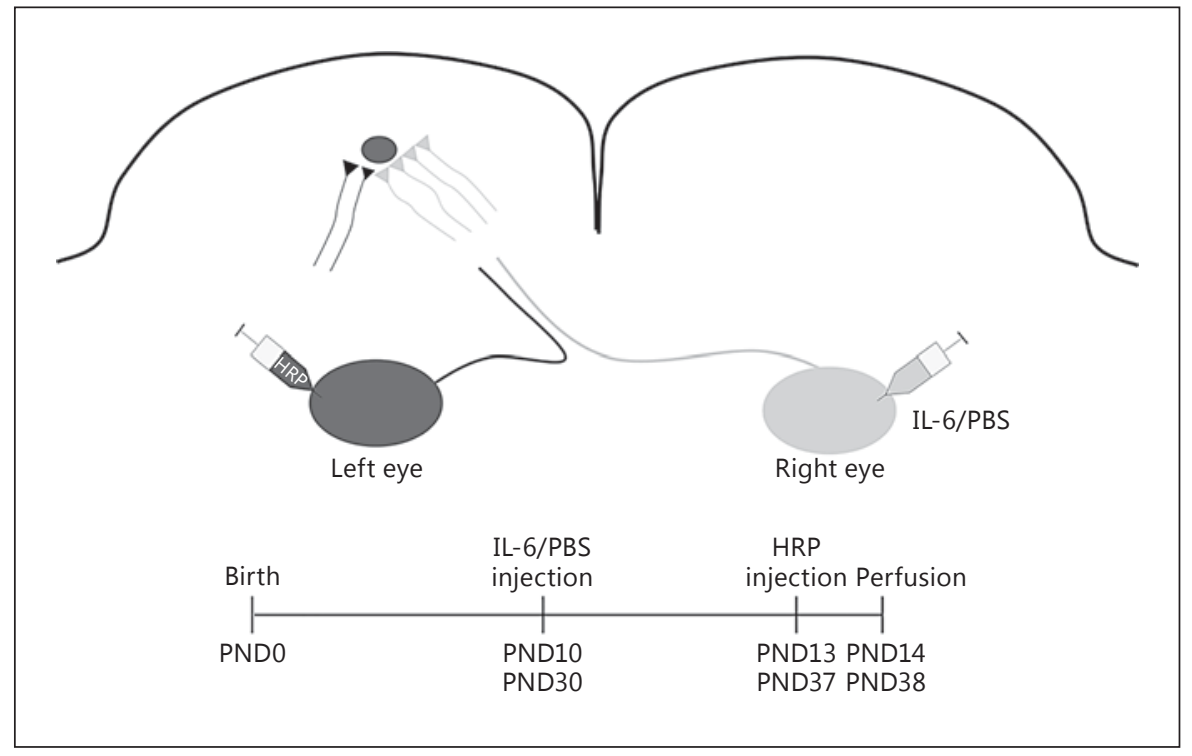

ing early postnatal days, appropriate connections are stabilized while the inappropriate synapses are eliminated [18]. As a consequence, uncrossed retinal fibers occupy the anterior third of the SC at the ventral border of visual layers while the contralateral fibers occupy the entire length of the collicular visual layers $[18,19]$. In rats, the critical period of these pathways extend until the third postnatal week [20]. Previously, our group demonstrated that different mechanisms are involved in the retinotectal development and plasticity [21-24]. Recently, we have shown that IL-2 intravitreous treatment during the critical period results in a sprouting of uncrossed retinotectal axons [25]. The aim of the present study was to evaluate the effect of a single intravitreous injection of IL-6 at different stages of development upon the distribution of retinal axons within the SC, which reveals the specificity of sensory circuits.

\section{Materials and Methods}

Lister Hooded rats were used according to the National Institutes of Health Guide for the Care and Use of Laboratory Animals. Experiments were approved by the Local Animal Care Committee (CEUA-UFF) under protocol 130/09. The studies were designed to minimize the number of animals used and their pain and suffering.

\section{Intravitreous Injections}

Animals received a single intravitreous injection of IL-6 ( $1 \mu \mathrm{l}$; $50 \mathrm{ng} / \mathrm{ml}$ recombinant human IL-6; Peprotech, Rocky Hill, N.J., USA) in the right eye, at either postnatal day (PND)10 or PND30.
Matched control animals received PBS injections as the vehicle. At PND13 or PND37 both groups (IL- or PBS-treated rats) were submitted to an intraocular injection of a 30\% solution of horseradish peroxidase (HRP; type VI, Sigma Chemical Co., St. Louis, Mo., USA) in $2 \%$ DMSO in the left, nontreated eye, in order to trace the uncrossed retinotectal projection (fig. 1) as previously described $[20,22]$. Animals presenting lens or retinal lesions during either procedure were discarded.

\section{Nissl Staining}

At PND14 or 38, the animals were euthanized with an overdose of isoflurane and perfused through the heart. The eyes were removed and fixed in $4 \%$ paraformaldehyde. The eyeballs were cryoprotected overnight in a series of sucrose solutions and frozen at the optimum cutting temperature. Orthogonal orientation slices were submitted to an ethanol series and stained with cresyl violet. The sections were dehydrated, mounted with Entellan (Merck, Rio de Janeiro, Brazil) and analyzed using a Leica microscope.

\section{Western Blot}

On PND14 or 38, the rats were deeply anesthetized by isoflurane inhalation and decapitated. The PBS- or IL-6 treated retinas were homogenized in ice-cold lysis buffer supplemented with a protease and phosphatase inhibitor cocktail (Thermo Scientific). The protein concentration was determined by the Bradford method [26]. From each sample, $60 \mu \mathrm{g}$ of protein were loaded in 10 or $15 \%$ SDS-polyacrylamide gels and electrotransferred to PVDF membranes (Amersham Biosciences, Piscataway, N.J., USA). After blocking for $2 \mathrm{~h}$ at room temperature with $5 \%$ nonfat milk in Tris-buffered saline plus $0.1 \%$ Tween 20 , the membranes were incubated overnight at $4{ }^{\circ} \mathrm{C}$ with primary antibodies (antirabbit-Ibal, 1:750; Wako; anti-mouse-GFAP, 1:2,500; Cell Signaling) and then with HRP-conjugated secondary antibodies (anti-rabbit, 1:5,000; BioRad; anti-mouse, 1:5,000; AmershamBioscience) for $2 \mathrm{~h}$ at room temperature. Bands were revealed using an ECL Plus chemiluminescent Kit (Amersham Biosci-
Menezes/Goulart/Espírito-Santo/ Oliveira-Silva/Serfaty/Campello-Costa 
ence) with a Chemi Express system (Loccus). To ensure that all lanes were loaded with the same amount of protein, the membranes were stripped and reprobed with ERK (1:1000; Santa Cruz Biotechnology, Santa Cruz, Calif., USA) or cyclophilin antibodies (1:750; Thermo Scientific). Densitometric analyses were performed with Scion Image for Windows software (Scion Corp., Frederick, Md., USA).

\section{HRP Histochemistry}

On PND14 or 38, the animals were euthanized with an overdose of isoflurane and perfused through the heart with saline $(0.9 \% \mathrm{NaCl})$ followed by Karnovsky solution (1\% paraformaldehyde and $2 \%$ glutaraldehyde in $0.1 \mathrm{M}$ phosphate buffer, $\mathrm{pH} 7.2$ ). The brains were removed, cryoprotected, frozen and sliced into $40-\mu \mathrm{m}$ coronal sections. The slices were processed while freefloating, as previously described [27]. The sections were analyzed under dark-field optics with polarization filters using a Leica microscope. The distribution of the uncrossed retinotectal terminal fields was measured in TIFF format images with Scion image software (Scion Image Beta 4.03; Scion Corp.). Sections were divided in three different regions of the SC. Samples were taken for five consecutive sections per animal centered at the peak density of the uncrossed terminal fields where clusters of ipsilateral axon terminals concentrate, i.e. the cluster region. Moreover, we also analyzed the five consecutive sections immediately before (the anterior region) and after (the posterior region) the cluster region. We evaluated the global pixel densities of terminal/fiber labeling to analyze the distribution of scattered fibers throughout the SC. Pixel densities were measured on a scale of $0-255$, which 255 corresponding to white. The density of the deeper, nonvisual area was used to analyze the background, which was subtracted from the global density of the visual layers in each section. Data were plotted using GraphPad Prism 5.0 software and statistically analyzed using Student's t test. Results were considered to be significant at $\mathrm{p}<0.05$.

\section{Results}

\section{A Single IL-6 Intravitreal Injection Does Not Lead to Retinal Inflammation}

Several studies have demonstrated multiple effects of cytokines upon the visual system $[25,28,29]$. Here, we investigated whether in vivo IL-6 treatment modulates the distribution of retinotectal axons during the development of visual circuits. Initially, we analyzed the retinal structure after a single intravitreous injection of IL- 6 during or after the critical period of retinotectal synaptic development. Figure 2 shows that both PBS and IL- 6 treatments did not recruit inflammatory cells or disrupted the histological integrity of the retina. Treated tissues did not present pyknotic nuclei and the retinal cytoarchitecture was preserved (fig. $2 \mathrm{a}-\mathrm{d}$ ). Also, we evaluated the content of Iba-1, a marker of activated macrophage and microglia, and also GFAP, a marker of astrocytes and Müller

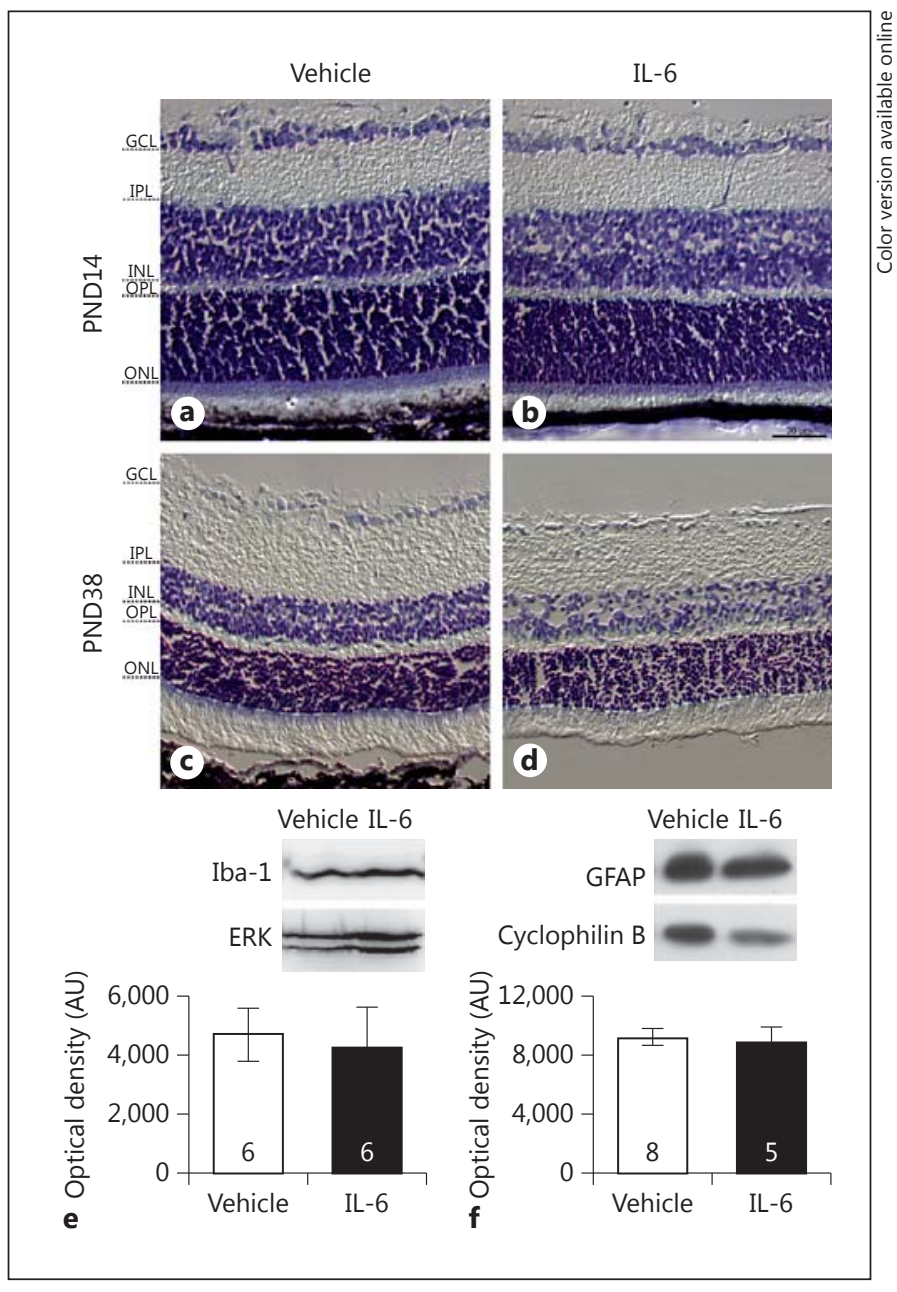

Fig. 2. Intravitreous treatment does not disrupt the retinal histological organization. Nissl staining of the retina in animals treated with PBS (controls; $\mathbf{a}, \mathbf{c}$ ) or IL-6 (b, d) on PND10 (a, b) or PND30 (c, d). GCL = Ganglion cells layer; IPL = inner plexiform layer; $\mathrm{INL}=$ inner nuclear layer; $\mathrm{OPL}=$ outer plexiform layer; $\mathrm{ONL}=$ outer nuclear layer. Scale bar $=20 \mu \mathrm{m}$. e, f Representative Western blots and corresponding densitometric analysis of whole-protein extracts of retinas from PBS- or IL-6-treated rats reacted with antiIba-1 (e) or anti-GFAP (f; above) that were reprobed with antiERK 1/2 (e) or cyclophilin (f) antibodies (below). Data represent the SEM of at least three independent experiments. The number of animals for each group is shown inside the bars.

cell activation in the retina [30]. No difference was found in either Iba-1 (fig. 2e) or GFAP (fig. 2f) levels between PBS- or IL-6-treated retinas, $96 \mathrm{~h}$ after eye injection. The same results were observed after $24 \mathrm{~h}$ of survival (data not shown). Taken together, these data suggest that a single IL-6 intravitreous injection at PND10 does not lead to an inflammatory response. 

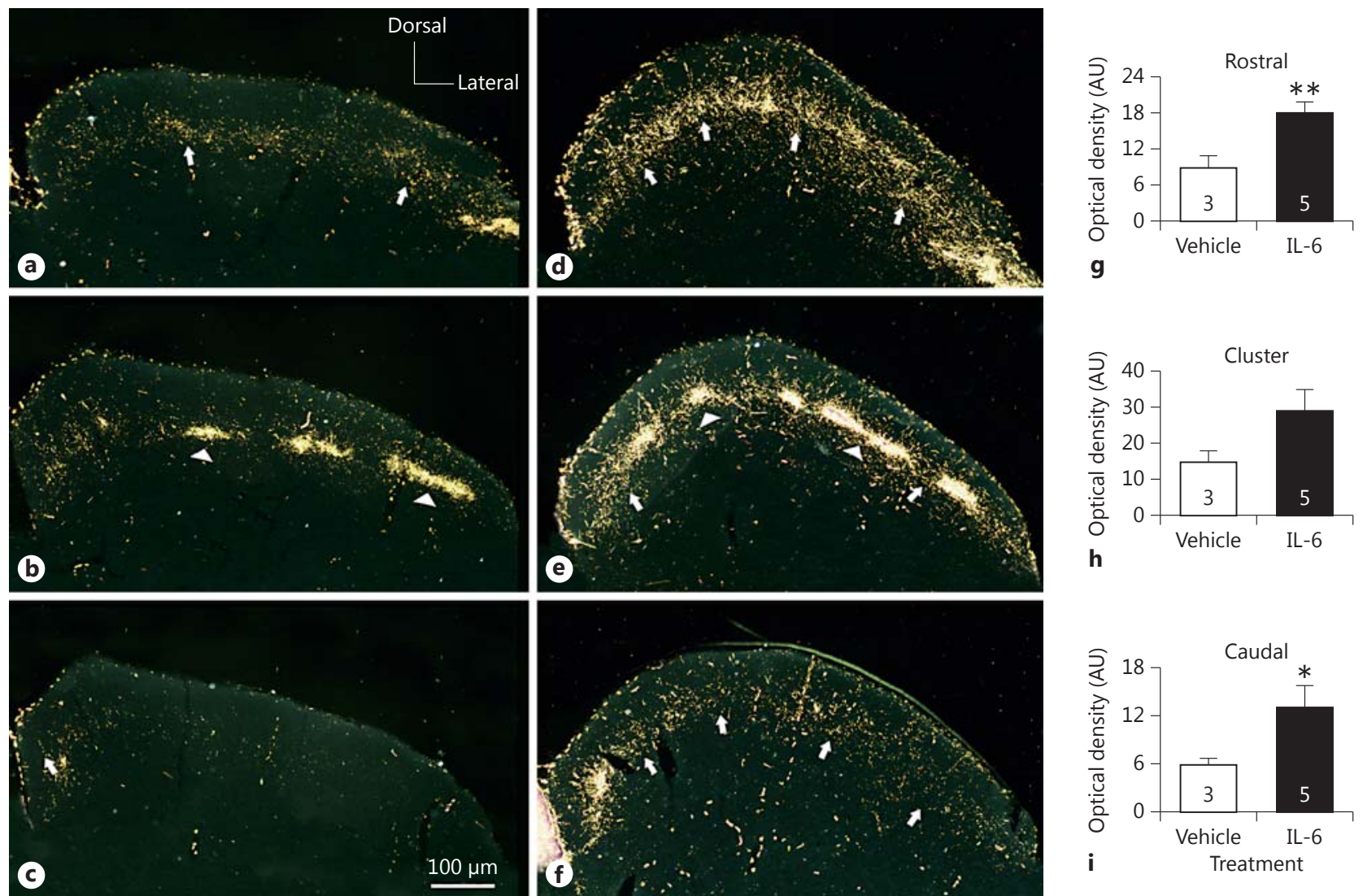

h

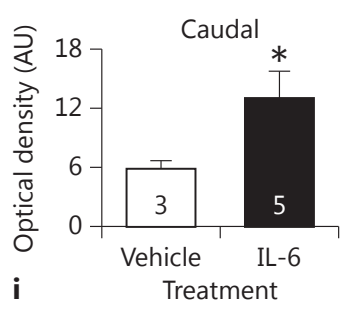

Fig. 3. Effect of IL-6 intravitreous treatment during the critical period of development. Dark-field photomicrographs showing coronal sections in different regions of the rat SC: PBS-treated animals (a-c); IL-6-treated animals (d-f); quantitative analysis of the glob- al optic density of uncrossed axons/terminals in the visual layers of the colliculus $(\mathbf{g}-\mathbf{i})$. Asterisks represent a significant difference: ${ }^{*} \mathrm{p}<0.05$; ${ }^{* *} \mathrm{p}<0.01 . \mathrm{n}=3$ or 5 animals for the PBS or IL- 6 treatment groups, respectively.
Effect of in vivo IL-6 Treatment upon the Development of Retinotectal Topography

The development of retinotectal topography was widely characterized in the literature by different groups $[23,24$, 31-33]. Different cytokines have been associated with the development and plasticity of the CNS $[9,34]$. Therefore, we decided to investigate the role of IL-6 upon retinotectal development. Our data revealed that on PND14, vehicletreated animals presented a normal uncrossed retinotectal axon distribution, as previously shown $[18,22,23]$. This pattern is characterized by the presence of some fibers rostrally (fig. 3a), a group of fibers condensed in a well-defined terminal zone located at the ventral stratum griseum superficiale (SGS) in the intermediate cluster region (fig. 3b), and rare fibers in the caudal area (fig. 3c). On the other hand, IL-6-treated animals presented fibers spread throughout the visual layers of the SC. In the rostral area, the presence of many fibers could be noted (fig. 3d) as well as in the intermediated region, where we detected not only the normal clusters of fibers in the SGS but also some fibers around it (fig. 3e). Moreover, IL-6-treated animals had many fibers in the caudal region of the SC (fig. 3f), which is normally an unrelated region for the ipsilateral pathway. Quantitative analysis of the global visual layers at these different regions confirmed the expansion of retinocollicular terminal fields in response to IL-6 (fig. 3g-i).

We also investigated whether IL-6 had any effect upon the retinotectal pathway in juvenile rats after the critical period. At PND38, PBS-treated animals presented an adultlike pattern of retinotectal axon distribution, with fibers clustered in the ventral SGS layer (fig. 4b) and few fibers in the rostral (fig. 4a) and caudal regions (fig. 4c). Meanwhile,
Menezes/Goulart/Espírito-Santo/ Oliveira-Silva/Serfaty/Campello-Costa 


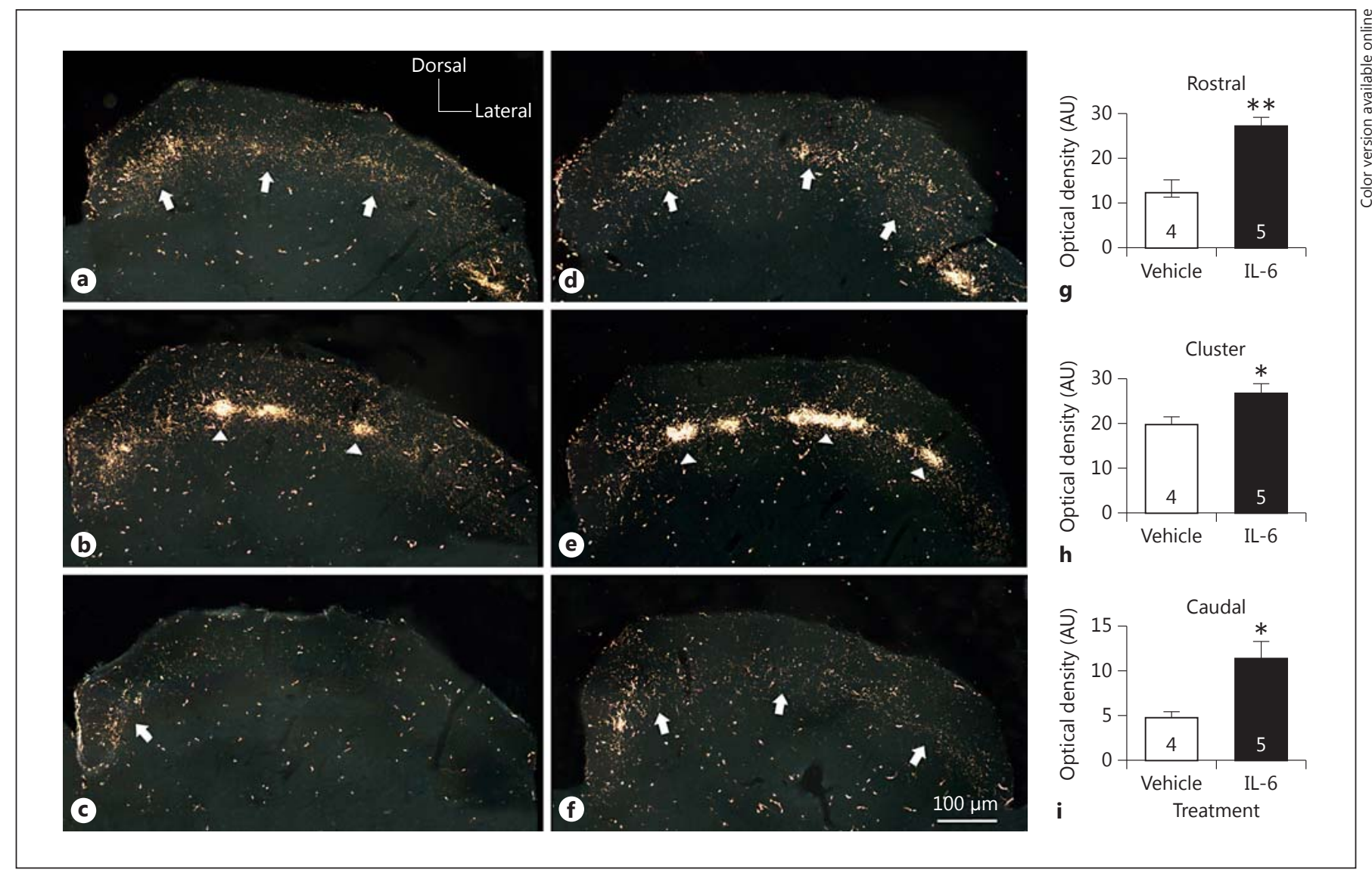

Fig. 4. Effect of IL-6 intravitreous injection after the critical period of development. Dark-field photomicrographs showing coronal sections at different regions of the rat SC on PND38: PBS-treated animals (a-c); IL-6-treated animals (d-f); quantitative analysis of the global optic density of uncrossed axons/terminals in the upper visual layers of the colliculus $(\mathbf{g}-\mathbf{i})$. Asterisks represent a significant difference: ${ }^{*} \mathrm{p}<0.05 ;{ }^{* *} \mathrm{p}<0.01$. $\mathrm{n}=4$ or 5 animals for the PBS or IL-6 treatment groups, respectively.
IL-6-treated rats presented fibers spread around the cluster region (fig. 4e) and more fibers spread in both the rostral (fig. 4d) and caudal (fig. 4f) colliculus. Indeed, quantitative analysis showed that the optic density is higher in IL6-treated animals compared to PBS-treated animals in all the analyzed areas (fig. 4g-i). These results collectively indicate that exogenous IL-6 treatment alters the distribution of retinal axons within the main subcortical target.

\section{Discussion}

It has been extensively shown that different kinds of cytokines are involved in physiological and pathological conditions in the CNS [35-37]. Here, we have shown for the first time the effect of an acute IL-6 intravitreal treatment on the development and maintenance of retinotectal axons.
Previously, we demonstrated the in vivo effect of chronic and acute IL-2 treatment on the subcortical visual circuitry refinement. The data showed that chronic treatment with either IL-2 or vehicle induces inflammation and plasticity in the uncrossed retinotectal axons. On the other hand, acute IL-2 intravitreous injection at an early stage of development leads to a rearrangement of the intact, nontreated eye without producing any intraretinal inflammation [25]. Therefore, in order to analyze the effect of IL-6 upon the retinotectal pathway, we decided to use a single intravitreous injection to avoid the presence of inflammation, which is recognized as an important element to induce plasticity [34, 38].

The comparison between the matched vehicle and IL-6 groups showed that a single intravitreous injection does not disrupt the histological organization of the retinal layers (fig. 2). Since the neuroimmune network in- 
cludes astrocytes and microglia activation, we also analyzed the effect of IL-6 upon different glial cell markers. Indeed, transgenic mice with IL- 6 overproduction develop reactive astrogliosis and an increase in ramified microglia [39]. Balasingam et al. [40] showed that IL-6 contributes to the production of gliosis measured by GFAP content. However, our data showed that Iba- 1 and GFAP levels were similar between the vehicle and IL- 6 groups (fig. 2), indicating that at the dose used IL-6 does not induce inflammation and glial cell activation in the developing retina. In fact, despite the classical role of IL- 6 on inflammation response, it is also directly involved in the regulation of a different neuronal process [41].

To examine whether IL-6 might contribute to the organization of visual connections, we evaluated the distributions of retinal afferents in the SC in early stages of development. At PND14, it was observed that animals treated with IL-6 presented an expansion in the uncrossed projections of the intact eye in different regions of the SC (fig. 3di) compared to controls (fig. 3a-c). The main effect is the presence of fibers in the caudal regions (fig. 3f, i), which indicate a topographical disruption since, at this age, the uncrossed axons are no longer seen in this region (fig. 3c) [18]. In order to evaluate if this effect is not restricted to the neonatal animals, at which stage retinotectal projections are more sensitive to the environment, a group of young adults received an IL-6 intraocular injection. Once again, after 1 week a single IL-6 treatment induces an increase of axonal sprouting in topographically unrelated regions of the SC (fig. 4). It has been well characterized that IL-6 increases the survival of RGCs in vitro [3-5] and in vivo [6, 7]. However, the data presented here could not be explained by the increase in the RGC population or a delay in the elimination of transient connections since the treatment with IL-6 was performed on PND10 or PND30, when the main retinal programmed cell death [42-44] and retinotectal pathway refinement [18] had already occurred. Corroborating our data, it has been shown that IL-6 intravitreous treatment increases neurite outgrowth of RGCs in culture and IL-6 knockout mice display a reduction in axonal outgrowth induced by optical nerve crush [38]. Besides, the proregenerative action of IL- 6 is also observed after cortical spinal tract injury. Additionally, in this model, IL-6 enhances synapse formation and functional recovery [45].

Our data showed that, after 4 or 8 days, IL- 6 intravitreous injection induces a sprouting of uncrossed axons from the intact, untreated eye, compared to controlmatched animals. In this time window we cannot exclude the idea that IL-6 could trigger the release of other mediators within the retina, which in turn could be respon- sible for the final effect on the reorganization of the retinotectal pathway. Furthermore, this data is also in agreement with previous work showing that temporal retinal lesions affect the distribution of axons from the intact eye [20]. This effect was explained by the interaction of binocular inputs on synaptic sites within the SC [46]. Thus, we hypothesized that exogenous IL- 6 triggers a different pattern of retinal activity, which in turn could be responsible for the reorganization of retinal afferents from the nontreated eye in the target.

In the retina, the expression of the full-length IL-6 receptor was detected both in ganglion cells and in cells of the inner nuclear layer, including Müller cells [38]. Therefore, the effect described herein for IL- 6 could be mediated by direct or indirect action on intraretinal connections. However, we did not observe any difference in the activation of glial cells in the retina after IL- 6 treatment, suggesting a direct effect on ganglion cell activity. In accordance with this idea, it was previously shown that IL-6 decreases $\mathrm{N}$-methyl-D-aspartate activity, weakening synaptic transmission $[8,47]$. Thus, it is reasonable to propose that IL-6 decreases retinal glutamatergic input to the SC favoring axonal sprouting of the opposite, nontreated eye.

In conclusion, our data present the first evidence that a single intravitreous injection with IL- 6 leads to the sprouting of uncrossed retinotectal fibers at different stages of development, indicating that this cytokine induces a plastic rearrangement even after the critical period. Taken together, these findings provide an important contribution to the understanding of the neuroimmune network involved in the development and disruption of specific patterns of connections in the central nervous system.

\section{Acknowledgments}

We thank Dr. Fabio Otero Ascoli for help with anesthetic procedures. This work was supported by grants from the FAPERJ (Fundação Carlos Chagas Filho de Amparo à pesquisa do Estado do Rio de Janeiro), CAPES (Coordenação de Aperfeiçoamento de Pessoal de Nível Superior), CNPq (Conselho Nacional de Desenvolvimento Científico e Tecnológico), PRONEX/MCT and PROPPi-UFF. G.D.M., V.G.G. and S.E.-S. were recipients of a CAPES fellowship.

References
86
Neuroimmunomodulation 2016;23:81-87 DOI: $10.1159 / 000444529$
Menezes/Goulart/Espírito-Santo/ Oliveira-Silva/Serfaty/Campello-Costa 
3 Mendonça-Torres PM, Giestal-de-Araujo E: Interleukin-6 increases the survival of retinal ganglion cells in vitro. J Neuroimmunol 2001; 117:43-50.

-4 Perígolo RV, Ritt K, Pereira MR, Torres PMM, Paes-de-Carvalho R, Giestal-de-Araujo E: IL-6 treatment increases the survival of retinal ganglion cells in vitro: the role of adenosine A1 receptor. Biochem Biophys Res Commun 2013; 430:512-518.

5 Perígolo-Vicente R, Ritt K, Gonçalves-de-Albuquerque CF, Castro-Faria-Neto HC, Paesde-Carvalho R, Giestal-de-Araujo E: IL-6, A1 and A2aR: a crosstalk that modulates BDNF and induces neuroprotection. Biochem Biophys Res Commun 2014;449:477-482.

6 Sappington RM, Chan M, Calkins DJ: Interleukin-6 protects retinal ganglion cells from pressure-induced death. Invest Ophthalmol Vis Sci 2006;47:2932-2942.

-7 Sims SM, Holmgren L, Cathcart HM, Sappington RM: Spatial regulation of interleukin-6 signaling in response to neurodegenerative stressors in the retina. Am J Neurodegener Dis 2012; 1:168-179.

8 Gruol DL: IL-6 regulation of synaptic function in the CNS. Neuropharmacol 2015;96:42-54.

-9 Bauer S, Kerr BJ, Patterson PH: The neuropoietic cytokine family in development, plasticity, disease and injury. Nat Rev Neurosci 2007;3: 221-232.

-10 Balschun D, Wetzel W, Rey A, Pitossi F, Schneider $\mathrm{H}$, Zuschratter W, Besedovsky HO: Interleukin-6: a cytokine to forget. FASEB J 2004;14: 1788-1790.

-11 Yirmiya R, Goshen I: Immune modulation of learning, memory, neural plasticity and neurogenesis. Brain Behav Immun 2011;25:181-213.

12 Wei H, Chadman KK, McCloskey DP, Sheikh AM, Malik M, Brown WT, Li X: Brain IL-6 elevation causes neuronal circuitry imbalances and mediates autism-like behaviors. Biochim Biophys Acta 2012;1822:831-842.

$\checkmark 13$ Shinoda Y, Sadakata T, Furuichi T: Animal models of autism spectrum disorder (ASD): a synaptic-level approach to autistic-like behavior in mice. Exp Anim 2013;62:71-78.

14 Bonnet-Brilhault F, Alirol S, Blanc R, Bazaud S, Marouillat S, Thépault RA, Andres CR, Lemonnier É, Barthélémy C, Raynaud $M$, Toutain A, Gomot M, Laumonnier F: GABA/glutamate synaptic pathways targeted by integrative genomic and electrophysiological explorations distinguish autism from intellectual disability. Mol Psychiatry 2016;21:411-418.

15 Wei H, Zou H, Sheikh AM, Malik M, Dobkin C, Brown WT, Li X: IL-6 is increased in the cerebellum of autistic brain and alters neural cell adhesion, migration and synaptic formation. J Neuroinflammation 2011;8:52.

16 Smith SE, Li J, Garbett K, Mirnics K, Patterson $\mathrm{PH}$ : Maternal immune activation alters fetal brain development through interleukin-6. J Neurosci 2007;27:10695-10702.

17 Debski EA, Cline HT: Activity-dependent mapping in the retinotectal projection. Curr Opin Neurobiol 2002;12:93-99.
Serfaty CA, Linden R: Development of abnormal lamination and binocular segregation in the retinotectal pathways of the rat. Brain Res Dev Brain Res 1994;82:35-44.

19 Isenmann S, Kretz A, Cellerino A: Molecular determinants of retinal ganglion cell development, survival, and regeneration. Prog Retin Eye Res 2003;22:483-543.

20 Serfaty CA, Campello-Costa P, Linden R: Rapid and long-term plasticity in the neonatal and adult retinotectal pathways following a retinal lesion. Brain Res Bull 2005;66:128-134.

21 Oliveira-Silva P, Jurgilas P B, Trindade P, 35 Campello-Costa P, Perales J, Savino W, Serfaty C A: Matrix metalloproteinase-9 is involved in the development and plasticity of retinotectal projections in rats. Neuroimmunomodulation 2007;14:144-149

22 Campello-Costa P, Fosse-Júnio AM, Ribeiro JC, Paes-de-Carvalho R, Serfaty CA: Acute blockade of nitric oxide synthesis induces disorganization and amplifies lesion-induced plasticity in the rat retinotectal projection. J Neurobiol 2000;44:371-381.

23 Campello-Costa P, Fosse-Júnior AM, OliveiraSilva P, Serfaty CA: Blockade of arachidonic acid pathway induces sprouting in the adult but not in the neonatal uncrossed retinotectal projection. Neuroscience 2006;139:979-989.

24 Tavares-Gomes AL, Maia FB, Oliveira-Silva P, Marques-Ventura AL, Paes-de-Carvalho R, Serfaty CA, Campello-Costa P: Purinergic modulation in the development of the rat uncrossed retinotectal pathway. Neuroscience 2009;163:1061-1068.

25 Espírito-Santo S, Mendonça HR, Menezes GD, Goulart VG, Gomes ALT, Marra C, Melibeu ACF, Serfaty CA, Sholl-Franco A, CampelloCosta P: Intravitreous interleukin-2 treatment and inflammation modulates glial cells activation and uncrossed retinotectal development. Neuroscience 2012;200:223-236.

26 Bradford, MM: A rapid and sensitive method for the quantitation of microgram quantities of protein utilizing the principle of protein-dye binding. Anal Biochem 1976;72:248-254.

27 Mesulam MM: Tetramethyl benzidine for horseradish peroxidase neurohistochemistry: a non-carcinogenic blue reaction product with superior sensitivity for visualizing neural afferents and efferents. J Histochem Cytochem 1978;26:106-117.

28 Sholl-Franco A, Figueiredo KG, Giestal-deAraujo E: Interleukin-2 and interleukin-4 increase the survival of retinal ganglion cells in culture. Neuroreport 2001;12:109-112.

29 Bialas AR, Stevens B: TGF- $\beta$ signaling regulates neuronal $\mathrm{Clq}$ expression and developmental synaptic refinement. Nat Neurosci 2013;16: 1773-1782.

30 Bringmann A, Pannicke T, Grosche J, Francke M, Wiedemann P, Skatchkov SN, Osborne NN, Reichenbach A: Muller cells in the healthy and diseased retina. Prog Retin Eye Res 2006;25: 397-424.

31 Land PW, Lund RD: Development of the rat's uncrossed retinotectal pathway and its relation to plasticity studies. Science 1979;205:698-700.
32 McLaughlin T, Torborg CL, Feller MB, O'Leary DD: Retinotopic map refinement requires spontaneous retinal waves during a brief critical period of development. Neuron 2003;40: 1147-1160.

33 Lo FS, Mize RR: Properties of LTD and LTP of retinocollicular synaptic transmission in the developing rat superior colliculus. Eur J Neurosci 2002;15:1421-1432.

34 Benowitz LI, Popovich PG: Inflammation and axon regeneration. Curr Opin Neurol 2011;24: 577-583.

35 Gadani SP, Walsh JT, Lukens JR, Kipnis J: Dealing with danger in the CNS: the response of the immune system to injury. Neuron 2015;87:4762.

36 Deverman BE, Patterson PH: Cytokines and CNS development. Neuron 2009;64:61-78.

37 Wei H, Alberts I, Li X: Brain IL-6 and autism. Neuroscience 2013;252:320-325.

38 Leibinger M, Müller A, Gobrecht P, Diekmann $\mathrm{H}$, Andreadaki A, Fischer D: Interleukin-6 contributes to CNS axon regeneration upon inflammatory stimulation. Cell Death Dis 2013; 25:4:e609.

39 Fattori E, Lazzaro D, Musiani P, Modesti A, Alonzi T, Ciliberto G: IL-6 expression in neurons of transgenic mice causes reactive astrocytosis and increase in ramified microglial cells but no neuronal damage. Eur J Neurosci 1995; 7:2441-2449.

40 Balasingam V, Tejada-Berges $\mathrm{T}$, Wright $\mathrm{E}$, Bouckova R, Yong VW: Reactive astrogliosis in the neonatal mouse brain and its modulation by cytokines. J Neurosci 1994;4:846-856.

41 Scheller J, Chalaris A, Schmidt-Arras D, RoseJohn S: The pro- and anti-inflammatory properties of the cytokine interleukin-6. Biochim Biophys Acta 2011;813:878-888.

42 Linden R, Rehen SK, Chiarini LB: Apoptosis in developing retinal tissue. Prog Retin Eye Res 1999; 18:133-165.

43 Perry VH, Henderson Z, Linden R: Postnatal changes in retinal ganglion cell and optic axon populations in the pigmented rat. J Comp Neurol 1983;219:356-368.

44 Dreher B, Potts RA, Bennett MR: Evidence that the early postnatal reduction in the number of rat retinal ganglion cells is due to a wave of ganglion cell death. Neurosci Lett 1983;36:255260.

45 Yang P, Wen H, Ou S, Cui J, Fan D: IL-6 promotes regeneration and functional recovery after cortical spinal tract injury by reactivating intrinsic growth program of neurons and enhancing synapse formation. Exp Neurol 2012; 236:19-27.

46 Serfaty CA, Linden R: Evidence that the relative densities of afferents from both eyes control laminar distribution and binocular segregation of retinotectal projections in rats. Dev Brain Res 1991;60:9-17.

47 Ma SH, Zhuang QX, Shen WX, Peng YP, Qiu YH: Interleukin-6 reduces NMDAR-mediated cytosolic $\mathrm{Ca}^{2+}$ overload and neuronal death via JAK/CaN signaling. Cell Calcium 2015;58:286295. 